
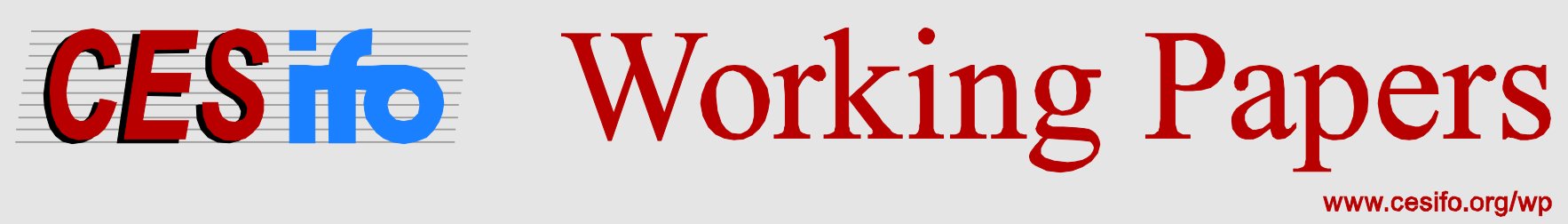

\title{
UK Natural Gas: \\ Gas-Specific or Oil Driven Pricing?
}

\author{
Frank Asche \\ Atle Oglend \\ Petter Osmundsen
}

\author{
CESIFO WORKING PAPER NO. 4503 \\ CATEGORY 9: RESOURCE AND ENVIRONMENT ECONOMICS \\ DECEMBER 2013
}

An electronic version of the paper may be downloaded

- from the SSRN website:

- from the RePEc website:

- from the CESifo website:

WWW.SSRN.com

www.RePEc.org

www.CESifo-group.org/wp

\section{CESifo}




\title{
UK Natural Gas: Gas-Specific or Oil Driven Pricing?
}

\begin{abstract}
In this paper we investigate the time-varying relationship between oil and natural gas in the UK. We develop a model where relative prices can move between pricing-regimes; markets switch between being decoupled and integrated. Our model endogenously accounts for periods where oil and natural gas temporarily decouple due to gas specific pricing. We show that gas-specific pricing is primarily related to fall/winter peak-load gas pricing and that mean reversion in relative prices is dependent on the time of the year. Most of the reversion back to oil occurs in spring and summer when demand for gas to heating and electricity is low and net-availability and transport capacity high. Accounting for periods of gas specific pricing is relevant when determining the long-run equilibrium value of oil relative to natural gas. Utilizing the regime where evidence is strongest for integrated markets we find that oil is historically priced at 2.3 times the value of natural gas in the UK, and that markets have been decoupled for $49 \%$ of the sample. Our results do not indicate that peak-load pricing has become more prevalent in recent years, i.e., we find no evidence of underinvestment in capacity after deregulation.
\end{abstract}

JEL-Code: Q310, Q410, Q470.

Keywords: oil, natural gas, seasonality, regime switching, demand, capacity, commodity price dynamics.

\author{
Frank Asche \\ University of Stavanger / Norway \\ Department of Industrial Economics \\ frank.asche@uis.no
}

\author{
Atle Oglend* \\ University of Stavanger / Norway \\ Department of Industrial Economics \\ atle.oglend@uis.no
}

\author{
Petter Osmundsen \\ University of Stavanger / Norway \\ Department of Industrial Economics \\ petter.osmundsen@uis.no
}

*corresponding author

Comments at 12th IAEE European energy conference, Venice 9-12 september 2012 is appreciated. We would also like to thank a number of specialists in business and the civil service for useful comments and proposals. Financial support from the Norwegian Research Council is appreciated. 


\section{Introduction}

The relative price of oil versus gas has been scrutinized in the literature. In particular, it has been tested whether deregulation of the gas market has led to decoupling of the oil and the natural gas price. To ascertain whether this has happened one has to account for seasonal fluctuations in the natural gas price. The relative price occasionally drops associated with seasonal peak-load pricing in natural gas, associated with a highly cyclical nature of the demand for natural gas. Thus, the natural gas market is not integrated og decoupled. Tather, it switches between the two states. However, the seasonal pattern is not regular across the sample. If gas-specific pricing only manifests when gas specific demand is close to availability and pipelines are at full-capacity, a linear model with a deterministic seasonality component will not capture this property. Seasonal peak-load pricing will with such analytical approach be imposed even in years where no seasonality is necessarily present, i.e., in warmer winters. An appropriate model for relative prices should have the flexibility to allow both peakload and non-peak-load pricing periods. When significant peak-load pricing is present, natural gas is valued by its immediate marginal productive value in generating electricity/heating in the home market. The price of oil is then likely not to be a major component in gas pricing. In this sense gas prices become decoupled from oil, and valuing gas relative to oil in these periods is not meaningful. Any arbitrage constraint on price differentials between oil and natural gas is likely only binding when natural-gas availability and transport capacity is sufficiently high. The peak-load prices manifest as asymmetrical persistent negative shocks to relative prices and will affect the empirical measure of relative values.

Interspersed periods of gas-specific pricing means that markets move between being decoupled and integrated. The likelihood of moving between pricing regimes will depend on market fundamentals such as gas-specific demand, gas availability and the pipeline infrastructure. A similar type of dynamics is investigated in electricity markets (Mount et al., 2006; Kanamura and Ohasi 2007; Geman and Roncoroni 2006). In electricity markets a hockey stick shaped supply curve gives rise to changes in pricing regimes within trading days. When capacity utilization is high in mornings and afternoons, electricity prices might spike and then quickly revert. Electricity and natural gas however differ form electicity at a fundamental level. The novelty of our paper is to adjust this approach and apply it to the natural gas market. Natural gas can be stored, allowing supply smoothing within certain capacity constraints. Storage ensures that demand shock effects can be distributed inter-temporarily. In 
this sense peak-load pricing is likely to be less extreme but more persistent than what observed in electricity markets.

Based on models used to characterize spikes in electricity prices we develop a regime switching model for oil/natural gas pricing which allows pricing to shift between two regimes. We are motivated by the possibility to account for the peak-load pricing effect in relative prices. Regime switching allows pricing to move between gas specific pricing (decoupled relative prices) or oil-dependent pricing (integrated markets) and/or seasonal or non-seasonal pricing. Contrary to electricity models, where peak-load pricing is incorporated by a price-jump regime, we allow price dynamics to change between two linear dynamic time-series models. Recognizing that variations in gas demand is likely to affect the probability of being in either regime, we use a temperature measure to proxy for seasonal gas demand. For modeling price spikes in electricity markets it is recognized that seasonal effects needs to be incorporated (Lucia and Schwartz, 2002). The same is true for peak-load pricing in natural gas markets. The direct use of gas for heating and electricity generation means seasonal demand is likely to affect the likelihood of changing pricing regimes. In our model temperatures are allowed to affect both the conditional mean of the relative price and the probability of changing regimes.

Our paper contributes to the literature on the relationship between natural gas and oil prices. A majority of studies in this area investigate the relationship by means of linear vector error correction models. We contribute by analyzing a non-linear model having the flexibility to account for periods of gas-specific pricing in the relationship. Moving to the family of non-linear models can shed light on facets of the price relationship not accounted for by linear models. Our results are important for at least two reasons. 1) There has been an effort to deregulate the EU market for natural gas to make the market more competitive (Asche et al., 2006; Panagiotidis and Ruthledge, 2007). However, there have also been suggestions that this will lead to underinvestment in infrastructure such as pipelines. If gas-specific pricing is becoming more prevalent, this can be interpreted as evidence that the regulations are succeeding in creating more competition. This gives better capacity utilization in the pipelines. If combined with weaker incentives to invest in upstream and transportation capacity, however, this may also create more and longer periods of peak load pricing. For this change to generate lower and less volatile gas prices in the time to come, one depends on the extent to which new fields will be developed under new market conditions. If oil and gas prices become decupled it will be difficult for gas buyers to enter into oil- 
linked contracts, as they will face hard competition from spot gas in periods of high oil prices. We still see new long-term contracts, but often linked to spot gas prices.

A crucial question is whether increased liquidity in the gas spot market provides sufficient guarantees to producers to recoup large and irreversible investments in new fields and pipelines. 2) A condition for determining an economically meaningful measure of the relative value of oil to natural gas is that the markets are integrated. If prices periodically decouple in one direction, such as for gas-specific pricing, an arithmetic mean of relative prices - or a linear specification between prices - will give a biased measure of the relative value. Our regime dependent model allows us to isolate periods where evidence is strongest for decoupled/integrated markets. Using the periods where evidence is strongest of integrated markets we find that oil is historically priced as 2.3 times the value of natural gas. Our results suggest that oil is valued higher relative to natural gas in the UK than what would be implied by a linear specification of relative prices. Our model also suggests that markets are decoupled in $49 \%$ of the sample.

\section{The literature}

The structure of the petroleum market has changed substantially during recent decades, primarily driven by deregulation of gas markets. This occurred first in the USA (DeVany and Walls, 1993; Doane and Spulber, 1994), and then in Europe; commencing in the UK and then increasingly in continental Europe (Asche et al., 2002; Silverstov et al., 2005; Asche et al., 2006). Until deregulation there was a direct link between oil and gas prices due to the pricing formulas used in long-term gas contracts. Moreover, there was little or no evidence of peak load pricing as local retail monopolies tended to overinvest in capacity. Although it was expected that deregulations should lead to gas-to-gas competition and a separate price determination process for gas (Doane and Spulber, 1994; DeVany and Walls, 1993; Asche et al., 2006), the link between oil and gas has prevailed. This is the case for the UK (Asche et al., 2006; Panagiotidis and Rutledge, 2007), and to a lesser degree the USA (Serletis and Herbert, 1999; Brown and Yucel, 2008; Bencivenga et al., 2011)².

\footnotetext{
${ }^{2}$ Oversupply of shale-gas in the USA has lead to a decoupling of U.S. natural-gas and oil prices since 2009 (Erdös, 2012).
} 

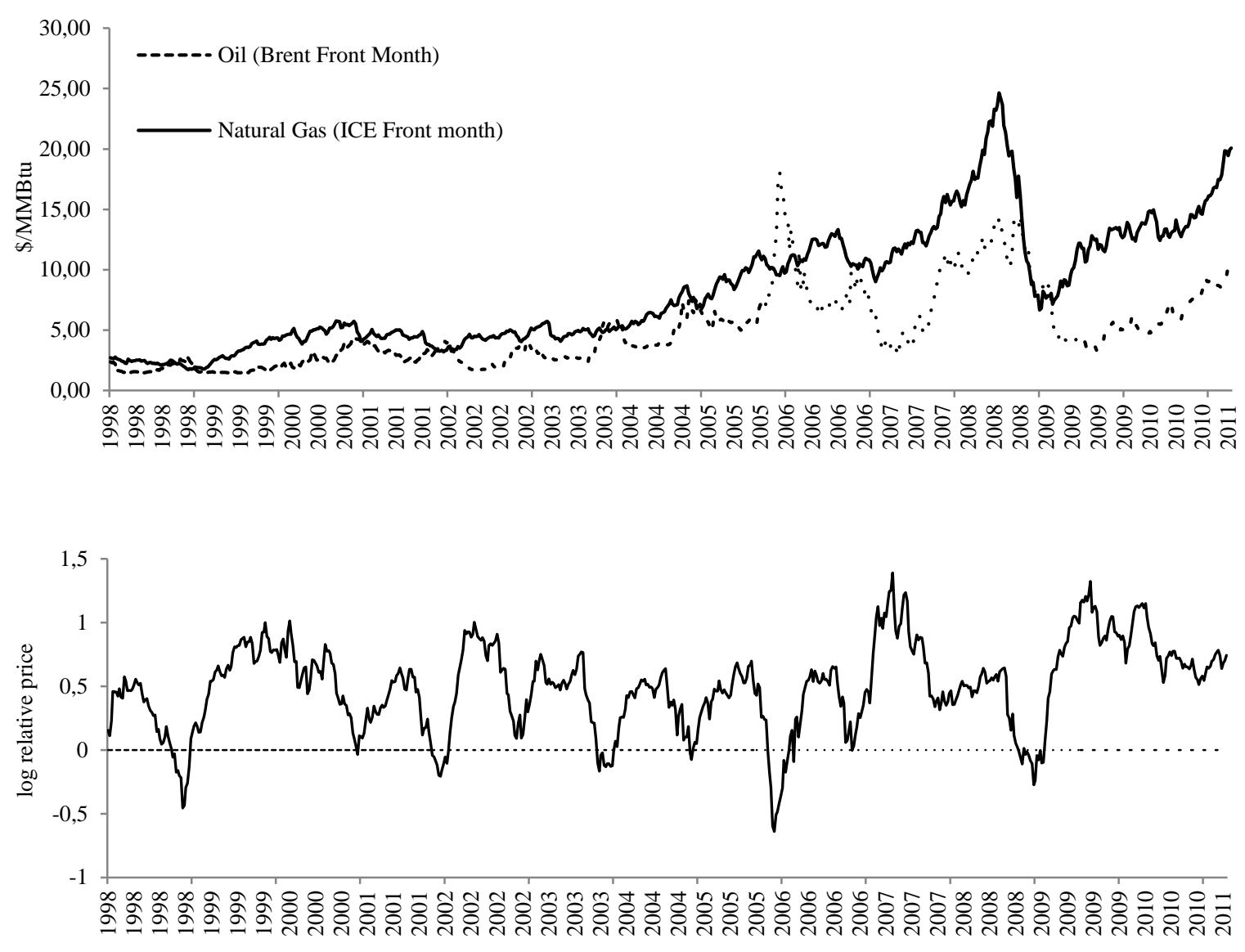

FIGURE 1. Oil (Brent front month) and Natural Gas (ICE front month) and corresponding log of relative price oil/natural gas (lower panel)

The development in Brent oil and ICE natural gas front month futures prices is shown in Figure 1. The figure also shows the logarithm of relative prices (oil divided by natural gas). Cointegration analysis indicates that oil and natural gas markets are integrated in the UK, with the law of one price holding (Asche et al. 2006; Panagiotidis and Ruthledge, 2007). In addition oil is generally found to be weakly exogenous (Asche et al., 2006). Even though markets are integrated there is substantial short-run variation in natural-gas prices not accounted for by oil. As is demonstrated in the relationship between natural gas (Henry Hub) and oil (WTI) in the U.S., additional variables such as temperature fluctuations are needed to account for short-run variations in gas prices (Ramberg and Pearsons, 2012). Figure 1 shows how relative prices occasionally drop associated with seasonal peak-load pricing in natural gas. However, the seasonal pattern is not regular across the sample. The spring of 2007 had high relative prices and the following fall/winter did not manifest in peak-load pricing This warrants a regime switching model for oil/natural gas pricing which allows pricing to shift between two regimes 
In the next section we give a brief overview of the markets for natural gas and oil in the UK and in section 4 we we discuss the effect of gas-specific pricing on the relative price relationship. We specify and estimate the regime-shifting model in section 5 and estimation results are presented in section 6. In section 7 the results are discussed and compared to a linear-model counterpart, and we.discusses implications for the value of oil relative to natural gas. Section 8 concludes.

\section{The Markets for Natural Gas and Oil in the UK}

During the last decades, demand for natural gas in the UK has more than doubled (Asche et al., 2008). This is largely due to the increased use of gas in the power sector. Combined cycle gas turbine technology in gas-fired power plants has increased fuel efficiency and requires lower capital and operating costs. Moreover, construction times are short, 2-3 years. This has led to a substantial increase in the use of natural gas for electricity generation in the UK. Gas-fired power primarily competes against coal and nuclear power, and the increase of the share of UK gas consumption for gas-fired power plants thus potentially contributes to a weaker link towards oil.

The price premium of oil relative to natural gas is limited over time due to substitution in consumption. If, e.g., natural gas becomes much cheaper than oil, there is an economic incentive for energy customers to switch to natural gas, and thereby contribute to a movement back to the historic mean relative price. Substitution and the resulting price correction, however, may be time consuming and therefore relative price imbalances may persist for some time. Some types of substitution is quick, e.g., for customers with dual burners. Other types of substitution often require investments. Substitution in such cases takes time. First the energy customers must be convinced that the price deviation will last long enough for them to recoup the investments; thereafter there is lead time on installation of new equipment (Bachmeier and Griffin, 2006). Other types of energy consumption cannot in the ordinary price range be substituted adequately with existing technology, e.g., oil still has an advantage over gas for transportation purposes. Long lasting price deviation from the historic mean level, however, may lead to R\&D that reduces this gap. The gas-to-liquid transformation cost imposes a cap on the oilgas price relation, and this technology might be expected to improve in cases of long lasting deviation from relative price mean. Generally, changes in consumption technology that only apply to oil or natural gas may trigger shifts in the price premium. 
Since natural gas in the UK is used for direct heating in addition to being a fuel input to electricity, it implies that demand is highly seasonal, correlated with temperatures. Demands typically peaks in winter, there is little air conditioning in the UK. Thus, natural gas prices are peakier since oil is not used significantly more in the heating season. However, this is not a consistent pattern. If natural gas availability is high, and the winter is mild, it is unlikely that seasonality in demand will be transmitted to prices. On the other hand, if demand and capacity utilization is high, seasonality in demand is more likely to transmit to price movements. If immediate gas availability is $A$ and consumption demand for gas is $Q$, the net availability of gas at any time is $X=A-Q$. As $X$ approaches zero, less gas is available to smooth further demand fluctuations and instantaneous price and volatility will increase. This property of storable commodity prices is well established in the competitive storage literature (Deaton and Laroque, 1992, 1996; Wright and Williams, 1991; Pirrong, 2012), where $X$ will denote amount of gas stored from one period to another.

Figure 2 below illustrates a possible market setup for pricing of natural gas and resulting relative prices. The cointegration relationship between oil and natural gas implies that a constant long-run equilibrium relative price exists. In the figure the equilibrium relative price (oil divided by gas) for a given oil price is denoted by $y^{e}$. Associated with this price is an equilibrium natural gas price $P^{e}$. For given gas availability, and marginal cost setup, a supply curve for natural gas exists. Equating with demand, the equilibrium natural gas price is established.
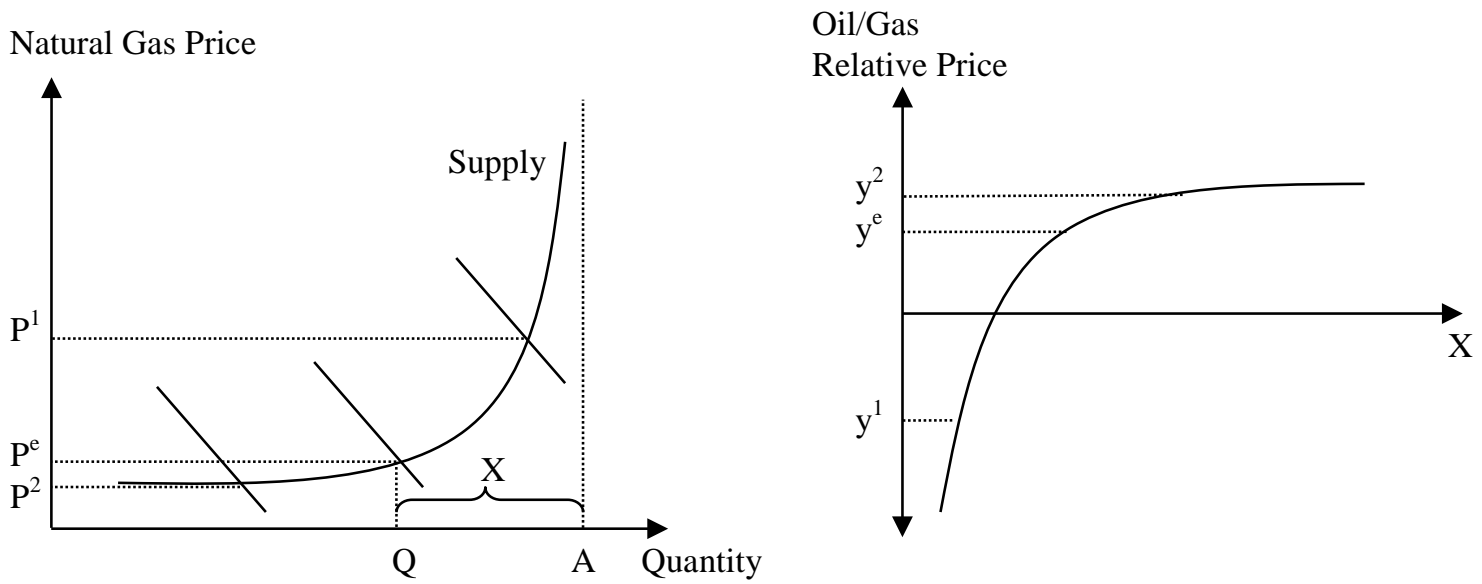

FIGURE 2. A setup for pricing of natural gas as and the oil/gas relative price

We assume oil supply to be weakly exogenous (Asche et al., 2003; Asche et al., 2006) and the supply curve of 
natural gas to be strictly convex. The question of interest is how natural-gas demand changes might affect observed relative prices. The given market setup implies that as capacity utilization becomes high (net availability low), natural gas prices start peaking, reaching for example $P^{2}$ in figure 2 . For relative prices this will result in a negative peak - point $y^{1}$ in the relative price figure. The relative price is pushed away from its long-run equilibrium. This will represent a period of diverging relative prices or decoupled prices. Once demand has reached its peak and eventually starts shifting back, relative price will revert back towards its long-run equilibrium level. Dependant on the convexity of the supply curve, the equilibrium relative price is relatively close to prices established when gas demand is low, as for example for prices $P^{2}$ and $y^{2}$ in the figure below. As such negative demand shifts (relative to the equilibrium relative price) will result in a relative price not easily identifiable from the equilibrium long-run relative price: $y^{2}$ is relatively close to $y^{e}$. This suggests that we can approximate the equilibrium long-run relative price better if we can account for the peak load pricing periods.

For a strictly convex supply curve the occasional peak-load pricing will manifest itself in negative spikes in relative prices. If these periods are not accounted for, the value of oil to natural gas will be underestimated. Valuing natural-gas by competing energy sources (such as oil in take-or-pay contracts) is not economically meaningful when natural gas is priced as a unique commodity in itself. Accounting for the peak-load pricing by a deterministic seasonal component will however overestimate the relative value. A linear dynamic model with deterministic seasonality is hence not sufficient to account for dynamics in relative prices. A rule of thumb in oil and natural gas prices is that oil should be twice the price of natural gas on an equivalent energy basis. In our data set, using the traditional method, we find the relative price to be $2 \ldots$. Thus, based on a linear time series model the rule of thumb will tend to overvalue the price relationship of natural gas relative to oil. This motivates the use of a flexible regime-switching model to account for the periods of gas-specific pricing.

In our model setup relative prices will decouple in periods where increasing demand pushes prices significantly away from the long-run equilibrium. Decoupled prices imply the relative price contains a unit-root (assuming the oil price contains a unit-root). Since natural gas demand is highly seasonal, this also suggests that the relative price contains a seasonal component in a decoupled regime. When natural gas demand shifts downward, relative prices will revert back to its long-run equilibrium level. Here markets are integrated, displaying mean reversion. Shifts between these regimes will depend on the net availability of natural gas. Investments in capacity will shift the supply curve out, increasing the threshold at which demand starts significantly affecting 
prices. Additional capacity will hence reduce peak-load pricing. Totally eliminating peak-load pricing in all years is likely to lead to excess capacity. It is not unreasonable that some years will contain peak-load pricing, while others not. A model for relative prices should allow for this.

\section{Temperature and Relative Prices}

Our measure of oil price is the crude oil Brent FOB front month futures price denoted in \$/MMbtu. The natural gas price is the ICE Natural Gas front month futures price, also denoted in \$/MMbtu. The National Balancing Point (NBP) in the UK is the pricing and delivery point for the ICE natural gas contracts. Strictly speaking, our results are only valid for the UK. However, as the European gas market is well integrated (Asche et al, 2002; Silverstov et al, 2005), the UK price can be regarded as a representation of the European price, and the qualitative results should be of interest also for the rest of the European gas market. As a measure of demand seasonality we use the London England Actual Weather Data mean temperature measure. All data are at a weekly frequency from week 1 in 1998 to week 15 in 2011. The oil and natural gas prices are shown in figure 1. We focus our analysis on the logarithm of the relative price of oil to natural gas: $y_{t}=\ln \left(\right.$ oilprice $\left._{t}\right)-$ $\ln \left(\right.$ gasprice $\left._{t}\right)$. The series is depicted in figure 1.

Figure 3 shows relative prices along with fitted values from the linear regression: $y_{t}=\mu+\beta$ temp $p_{t}+\varepsilon_{t}$, with $\mu$ an intercept, temp $_{t}$ temperature and $\varepsilon_{t}$ model errors.

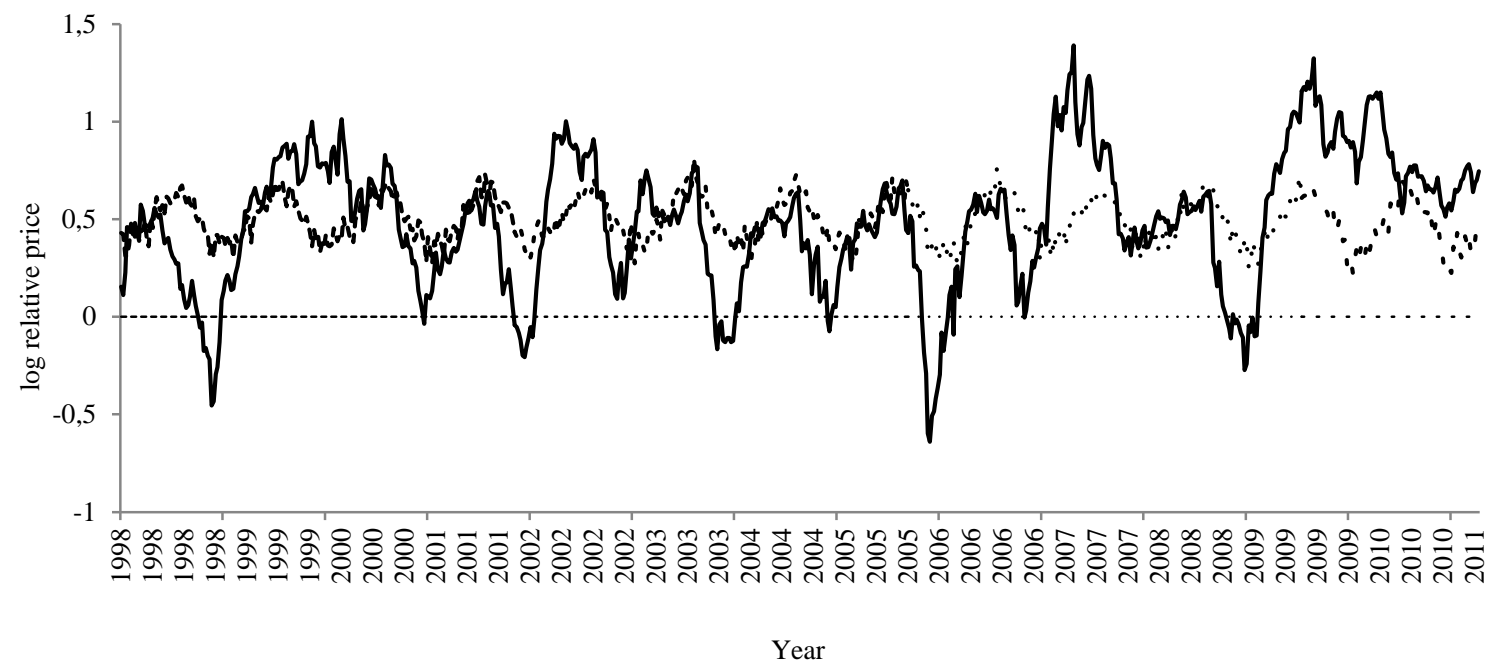

FIGURE 3. The oil/gas relative price (black line) and fitted temperatures (dotted line). 
The negative peaks in relative prices are associated with lower temperatures. The regression illustrates how the simple linear temperature model predicts the timing of seasonality in seasonal years, but that it fails to account for 1) the magnitude of the seasonal effect 2) the lack of seasonal effects in years with no apparent seasonality, such as for example the 1999/2000 and 2009/2010 seasons.

Our baseline empirical model is a first order autoregressive model with temperature accounting for seasonal effects:

$$
y_{t+1}=\mu+\beta y_{t}+\gamma t e m p_{t}+\sigma \varepsilon_{t+1},
$$

In equation (1) $y_{t+1}$ is next week’s log relative price, $\ln \left(\frac{o i l_{t+1}}{\text { gas }_{t+1}}\right), \mu$ an intercept and temp $p_{t}$ current week temperature. $\sigma$ is the standard-deviation of the error-term $\varepsilon_{t}$. Estimation results are shown in table 1 . Note the high degree of shock persistence. The implied half-life of a shock to relative prices is approximately 47 weeks, nearly a year. The effect of the significantly negative temperature measure is to adjust the dynamic effect of shocks. This highlights the seasonally dependent dynamics in the series. When temperatures are high, the temperature adjusts the conditional mean price downwards in anticipation of starting fall/winter pricing for the front month futures. When temperatures are low, conditional mean price increases in anticipation of higher prices.

TABLE 1. Linear Seasonal Model

\begin{tabular}{|c|c|c|c|c|c|}
\hline & Coef. & Std.Dev. & Specification tests & value & p-value \\
\hline$\mu$ & 0.0422 & 0.0078 & Portmanteau(24) & 51.126 & 0.0007 \\
\hline$\beta$ & 0.9854 & 0.0095 & Autocorrelation (24) & 44.384 & 0.0069 \\
\hline$\gamma$ & -0.0028 & 0.0006 & ARCH 1-12 & 3.0997 & 0.0003 \\
\hline \multirow[t]{2}{*}{$\sigma$} & 0.2832 & & Asymptotic Normality & 131.43 & 0.0000 \\
\hline & & & Normality & 47.441 & 0.0000 \\
\hline $\mathrm{N}$ & 691 & & & & \\
\hline \multirow[t]{2}{*}{ Log- Likelihood } & 764.15 & & Skewness & -0.6162 & \\
\hline & & & Kurtosis & 1.7452 & \\
\hline
\end{tabular}

Note: Portmanteau test is carried out with 24 lags, null distribution is $\chi^{2}(23)$. Autocorrelation test is also carried out with 24 lags, null distribution is $\chi^{2}(24)$. ARCH 1-12 test refers to the test for ARCH effects of lags up to 12. Null distribution is $\mathrm{F}(12,667)$. Tests for normality has null distribution $\chi^{2}(2)$.

The effect of seasonality on dynamics is confirmed if we estimate the model without temperature. In this instance the autoregressive coefficient drops to 0.9705. A lack of linear effects is confirmed by the non-linearity Core Index test (Castle and Hendry, 2010). The test is based on orthogonalized regressors and is distributed as 
$\chi^{2}(6)$ under the null of linearity. The test strongly rejects linearity. ${ }^{3}$ Miss-specification from the linear model is apparent when looking at misspecification tests. There is evidence of significant residual autocorrelation in addition to ARCH effects. We strongly reject normality - there is excess kurtosis and negative skewness. The negative skewness is likely due to the natural-gas peak-load pricing.

\section{A Seasonal Regime Switching Model}

The regime model in this section is based on the regime shifting model of Hamilton (1989) and Hamilton and Susmel (1994). Since its introduction the regime switching model has become popular in non-linear time-series modeling. It is by now a staple model in the class of non-linear time series models. Applications of the model can be found in the business cycle literature (Hamilton, 1989; Bansal et al., 2004), and in interest rate modeling (Garcia and Perron, 1996; Gray, 1999; Ang and Bekaert 2002). In commodity markets the model has been popular when modeling electricity prices (Mount et al., 2006; Kanamura and Ohasi, 2007). In the original regime switching model the probability of changing regimes depended on a constant probability transition matrix. This was later relaxed to allow the probability transition matrix to change dependent on predetermined driving variables (Diebold et al., 1994). Since regime switching is likely to depend on underlying factors, it is this model setup we utilize to analyze relative prices of oil and natural gas.

The purpose of the regime switching model is to addresses the shortcomings of the linear dynamic seasonal model. We wish to develop a model which better incorporates the periodic peak load pricing effect in the oil/gas relationship. The model is fundamentally based on the assumption of a convex supply curve for natural gas and an exogenous oil price. Relative price is allowed to move between two regimes, where the regimes are $a$ priori identical but can potentially account for the non-linear effect of prices moving along a convex supply curve.

We assume the relative price $\left(y_{t}\right)$ can change between two a priori identical pricing regimes. Relative prices in each regime follow the same dynamics as in the linear seasonal dynamic model:

$$
y_{t+1}=\mu_{R}+\beta_{R} y_{t}+\gamma_{R} t e m p_{t}+\sigma_{R} \varepsilon_{t+1},
$$

\footnotetext{
${ }^{3}$ The p-value is 0.0019 .
} 
where $R=[1,2]$ denote the regime at time $t$. In the original two-state model, the regimes change is conditional on a constant probability transition matrix:

$$
P=\left[\begin{array}{cc}
p_{11} & 1-p_{22} \\
1-p_{11} & p_{22}
\end{array}\right]
$$

where $p_{i i}$ is probability of remaining in regime $i$ in the next period if price is in regime $i$ today. We can summarize the state of the market at time $t$, conditional on information at time $t$, in the [2×1] vector $S_{t \mid t}$, where row $i$ is equal to 1 if the market is in regime 1 and zero otherwise. The expected next period regime is then equal to $S_{t+1 \mid t}=P S_{t \mid t}$. Note that $S_{t \mid t}$ can be interpreted as the probability of existing in either regime at time $t$ based on information at time $t$. Assuming a starting state $S_{0 \mid 0}$, this allows a recursive projection and updating procedure where probabilities of existing in either regime at time $t$ can be derived. Details on the implementation of the classical regime switching model can be found in Hamilton (1994).

The constant transition probability matrix imposes non-duration dependence on regimes. This restriction has been found to be invalid in electricity markets (Kanamura and Ohasi, 2007). Our model setup also suggests transition probabilities should vary with demand fluctuations, and hence be correlated with temperatures. This implies that the transition probability matrix is seasonal. Note that seasonal fluctuations in transition probabilities mean that seasonal pricing is stochastic - the model allows for prices in some years not to display seasonality. This is not allowed if seasonality is imposed on the conditional mean equation only, as in the linear seasonal model.

The transition probability matrix is modeled by a logistic function dependent on current week temperature:

$$
p_{11, t}=\frac{\exp \left(\alpha_{1,1}+\alpha_{1,2} \text { temp }_{t}\right)}{1+\exp \left(\alpha_{1,1}+\alpha_{1,2} \text { temp }_{t}\right)}, \quad p_{22, t}=\frac{\exp \left(\alpha_{2,1}+\alpha_{2,2} t e m p_{t}\right)}{1+\exp \left(\alpha_{2,1}+\alpha_{2,2} t e m p_{t}\right)}
$$

Given parameter values we can form the likelihood at time $t+1$ as $f_{t+1}=\left(P_{t} S_{t \mid t}\right)^{\prime} F_{t+1}$, where $F_{t+1}$ is the $[2 \times 1]$ vector of likelihoods for each individual regime at time $t+1$ and $P_{t}$ is the probability transition matrix with elements given by equation (4). For a starting state, which we assume to be the steady state, the sum of the log likelihoods over the sample can be maximized using conventional maximum likelihood methods. Given 
estimated parameters we run a backwards recursion deriving regime probabilities incorporating the full sample information. This produces the smoothed regime probabilities $S_{t \mid T}$. For further information on estimation of the model see Mount and Xiaobin (2006).

Two hypotheses are of specific interest when evaluating the model. The first relates to the seasonality in the conditional mean relative price. Will pricing move between regimes with and without seasonality in the conditional mean? For this to be the case the temperature coefficient must satisfy $\gamma_{i} \neq 0$ and $\gamma_{j}=0$ for $i, j=$ 1,2. The restriction is tested using a standard likelihood-ratio test. Another hypothesis of interest is whether markets move between being decoupled and integrated. Decoupled prices imply that the relative price has a unitroot. In our model setup this implies that $\beta_{i}=1$ and $\beta_{j}<1$ for $i, j=1,2$. Given the non-standard asymptotic distribution of $\beta_{i}$ in the presence of a unit-root, we evaluate this hypothesis by bootstrapping. We derive the finite sample distribution of $\beta_{i}$ under the null of a unit-root in one of regimes.

\section{Estimation Results}

The output from estimating the unrestricted regime switching model is reported in table 2 . The model has eight more parameters than the linear model counterpart. Since the models are non-nested, we cannot apply conventional likelihood ratio tests to discriminate between models.

TABLE 2. Regime Switching Model with Time Varying Transition Probabilities

\begin{tabular}{|c|c|c|c|c|c|c|c|}
\hline & \multicolumn{2}{|c|}{ Regime 1} & \multicolumn{2}{|c|}{ Regime 2} & \multirow[b]{2}{*}{ Specification Tests } & \multirow[b]{2}{*}{ Value } & \multirow[b]{2}{*}{ p-value } \\
\hline & Coef. & Std.Dev & Coef. & Std.Dev & & & \\
\hline Mean Equation & & & & & Portmanteau(24) & 32.625 & 0.1122 \\
\hline$\mu$ & 0.0553 & 0.0089 & 0.0464 & 0.0132 & Autocorrelation (24) & 31.927 & 0.1288 \\
\hline$\beta$ & 0.9345 & 0.0119 & 0.9967 & 0.0145 & ARCH 1-12 & 0.9187 & 0.5275 \\
\hline$\gamma$ & -0.0004 & 0.0005 & -0.0046 & 0.0012 & Asymptotic Normality & 9.3746 & 0.0092 \\
\hline$\sigma$ & 0.0514 & & 0.0975 & & Normality & 7.4728 & 0.0238 \\
\hline Prob. Equation & & & & & Skewness & -0.2085 & \\
\hline$\alpha_{1}$ & 10.8377 & 3.6261 & 1.2742 & 0.8598 & Kurtosis & 0.3764 & \\
\hline$\alpha_{2}$ & -0.4357 & 0.1799 & 0.2339 & 0.1305 & & & \\
\hline $\mathrm{N}$ & 691 & & & & & & \\
\hline Log- Likelihood & 818.95 & & & & & & \\
\hline
\end{tabular}

Note: Portmanteau test is carried out with 24 lags, null distribution is $\chi^{2}(23)$. Autocorrelation test is also carried out with 24 lags, null distribution is $\chi^{2}(24)$. ARCH 1-12 test refers to the test for ARCH effects of lags up to 12. Null distribution is $\mathrm{F}(12,667)$. Tests for normality has null distribution $\chi^{2}(2)$ 
To address the concern that the linear model might generate dynamics similar to the regime switching model, we derive finite sample likelihood-ratio statistics by bootstrapping. We simulate 1000 time series realizations of the linear model estimated above (table 1).The lengths of the simulated series are set equal to the length of the original data. The simulated series are estimated using the regime switching model to arrive at likelihood ratios. If the models where nested the likelihood ratio statistics should be distributed as $\chi^{2}(8)$ under the null. The 95\%/99\% percentiles of the bootstrapped likelihood-ratios are (16.83/23.05). These are not too far from the $\chi^{2}(8)$ values $(15.5 / 20.1)$. The likelihood ratio for the model estimated on real data is 109.62 . This provides statistical evidence against the linear dynamic model generating dynamics similar to the regime switching model.

Model comparison can also be done by evaluating how well competing models encompass the data. Contrary to the linear dynamic model there is much weaker evidence for residual autocorrelation in the regime switching model. In addition ARCH effects are accounted for. Since we allow conditional variance to change between regimes, conditional variance is not constant in the regime switching model. The model also accounts for more of the skewness and kurtosis in the data. Overall, the statistical evidence favours the regime switching model over the linear model.

\section{Implications for the value of oil relative to natural gas}

Comparing dynamics in the two regimes, we find significant difference in both the conditional mean and variance. Regime 1 is characterized by mean-reversion (half-life of shocks is only 10 weeks), no seasonal effects in the conditional mean and lower volatility. For regime 2 we find weak evidence for mean-reversion, seasonal effects in the conditional mean and larger price volatility. The smoothed probability of existing in regime 2 and the relative prices are shown in figure 4 .

Regime 2 (with low mean reversion and significant temperature effects) tends to account for the major downward movements in relative prices in addition to the negative peak prices. These are periods associated with increasing gas prices. Conceptually these periods are where increasing gas demand pushes prices significantly upwards on the supply curve. Regime 1 (mean-reversion, no significant seasonality) is associated with periods where prices are increasing and stable. These are periods associated with lower gas prices. The 
regime switching is fairly regular in certain periods, like the early 2000 to 2006 period. However, it is less regular in the start and at the end of the sample.

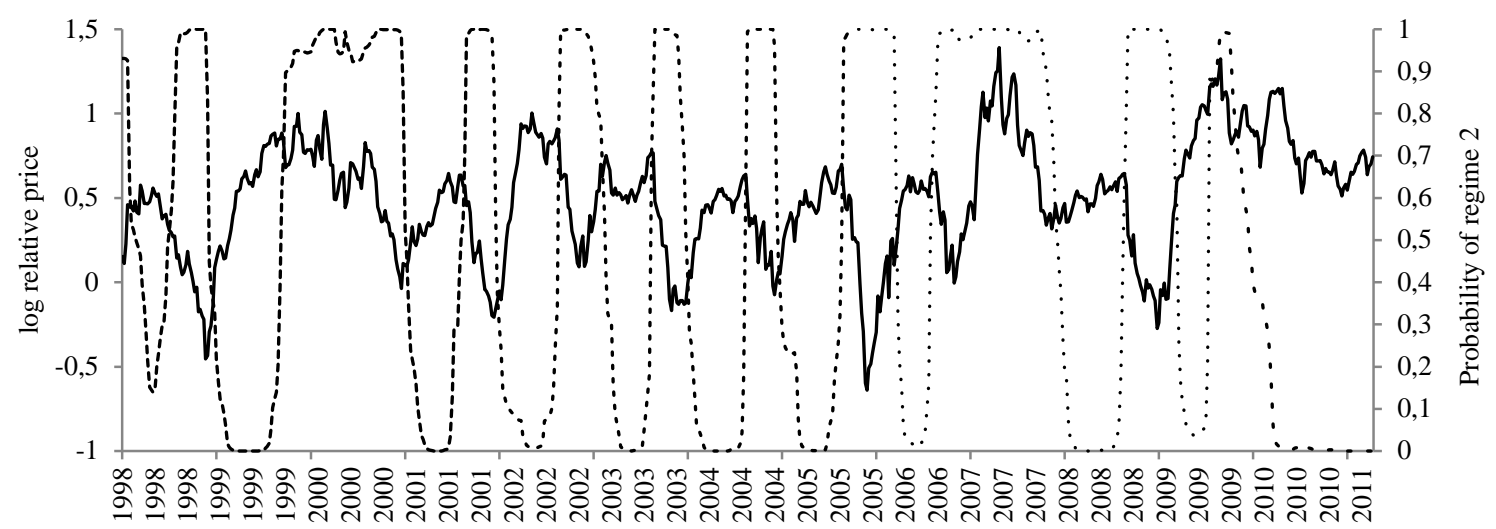

Year

FIGURE 4. The oil/gas relative price and the smoothed probability of being in regime 2 .

Our results suggest that pricing moves between a decoupled regime with significant seasonality (regime 2), and a stable/less volatile integrated regime (regime 1). The hypothesis that prices move between seasonal/non-seasonal pricing regimes can be tested by imposing the restriction that one of regimes have no significant temperature effects in the conditional mean. We test this by re-estimating the model with the restriction that the temperature effect is zero in regime $1\left(\gamma_{1}=0\right)$. The p-value for the restriction is 0.5341 . Given that regime 2 shows weak evidence for mean-reversion, we would like to evaluate whether regime 2 can be characterized by a unit-root process. We do this by imposing the restriction $\beta_{2}=1$. The p-value for the restriction is 0.8671 . Testing both restrictions simultaneously produces a p-value of 0.5071. Imposing a unit-root in one of the regimes is however not straight forward. Under the null of a unit-root in one of the regimes the asymptotic distribution of $\beta_{1}$ is nonstandard. To investigate the finite-sample distribution of $\beta_{1}$ under the null of a unit-root we bootstrap the distribution. We do this by simulating 1000 time-series realizations of the original regime switching model under the restriction that $\gamma_{1}=0$ and $\beta_{2}=1$. The simulated series have the same length as the original series. The simulated data by construction moves between a unit-root and non-unit-root regime. Figure 5 show the bootstrapped distributions.

The mean(median) for $\beta_{2}$ is $0.9942(0.9924)$. Standard deviation for $\beta_{2}$ is 0.0135 . The distribution is negatively skewed (-0.97). There is a slight downward bias in the mean relative to the null unit value. The mean(median) for $\beta_{1}$ is $0.9413(0.9413)$ with a standard deviation of 0.01 . The negative skeweness is somewhat reduced $(-0.49)$. There is a slight upward bias for the mean of $\beta_{1}$ (null value for simulated series is 0.9345). The 
positive(negative) bias in mean estimates is possibly due to the difficulty in differentiating between regimes for certain simulated series, for $1 \%$ of the estimates $\beta_{1}>\beta_{2}$. Overall, however, the bootstrap results show that the model estimation can reasonably well differentiate between regimes. The bootstrapped standard-deviations are also fairly close to the asymptotic standard-deviations in table 2 . The 5\%/95\% confidence interval for $\beta_{1}$ and $\beta_{2}$ using the finite-sample distribution is $(0.9231 / 0.9556)$ and $(0.9668 / 1.0111)$. The unrestricted estimate for the autoregressive coefficient in regime 2 was $\beta_{2}=0.9967$. The probability that the model with a unit-root in the regimes produces a coefficient lower than this is 0.593 . Furthermore, none of the estimates in the mean-reverting regime produces such a high value (the highest estimate for $\beta_{1}$ in the bootstrap estimation was 0.97). The bootstrapping exercise shows that evidence against a hypothesis that relative prices move between an integrated mean-reverting and a decoupled unit-root regime is weak.

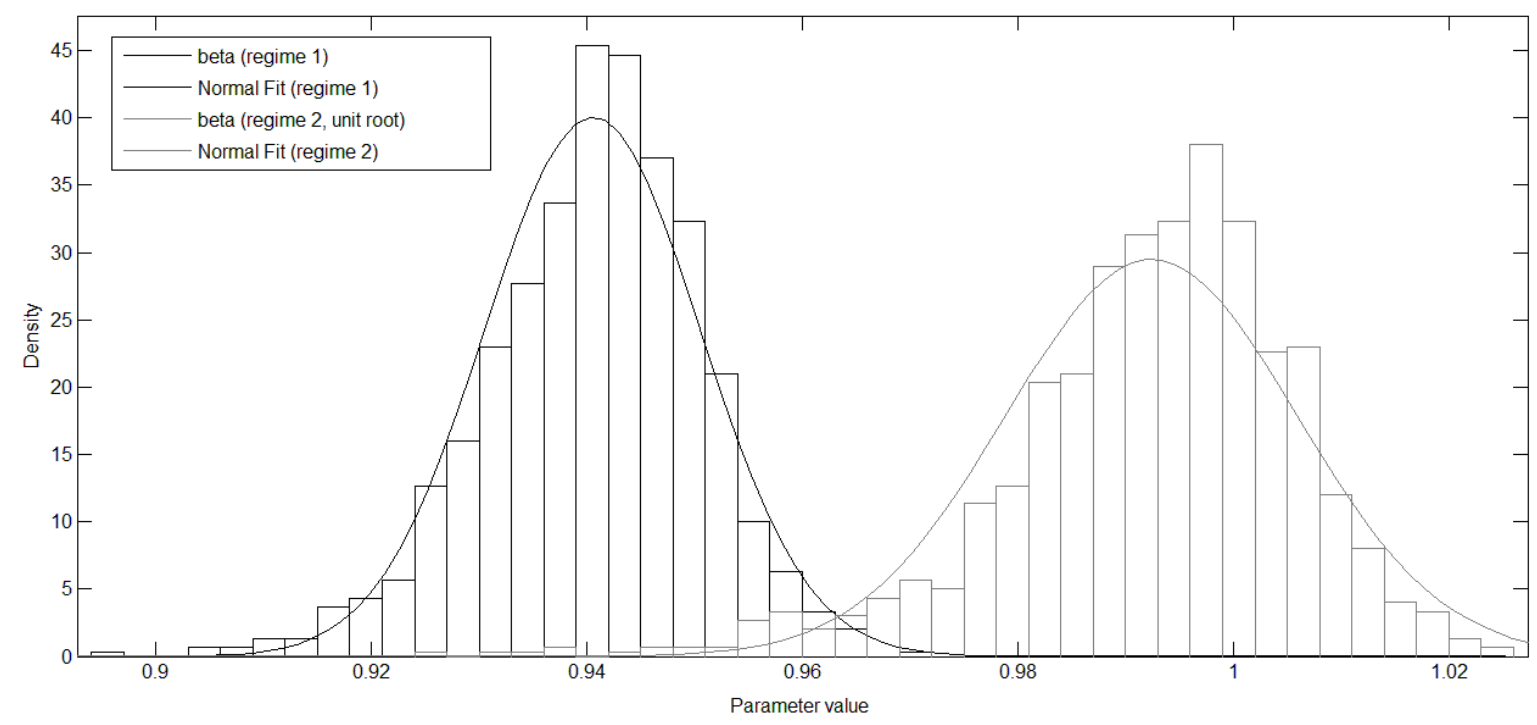

FIGURE 5. Bootstrapped distributions of $\beta_{1}$ and $\beta_{2}$ under the null that $\beta_{1}=0.9345$ and $\beta_{2}=1$.

The empirical results suggest that relative prices move between an integrated and a non-integrated regime. In the non-integrated regime the gas price is decoupled from oil and contains a seasonal component related to the occasional seasonal peak-load pricing. When temperatures starts increasing in later winter, demand decreases, and natural gas is more likely to be integrated with oil. This suggests that an equilibrium relationship between the energy carriers is more likely to manifest when consumption demand is relatively low and transport/production capacity available. To investigate the model dynamics further we simulate 1000 realizations of the regime switching model using the fit from table 2. Each simulation starts at the first price observations and uses the states implied by the estimated model. 


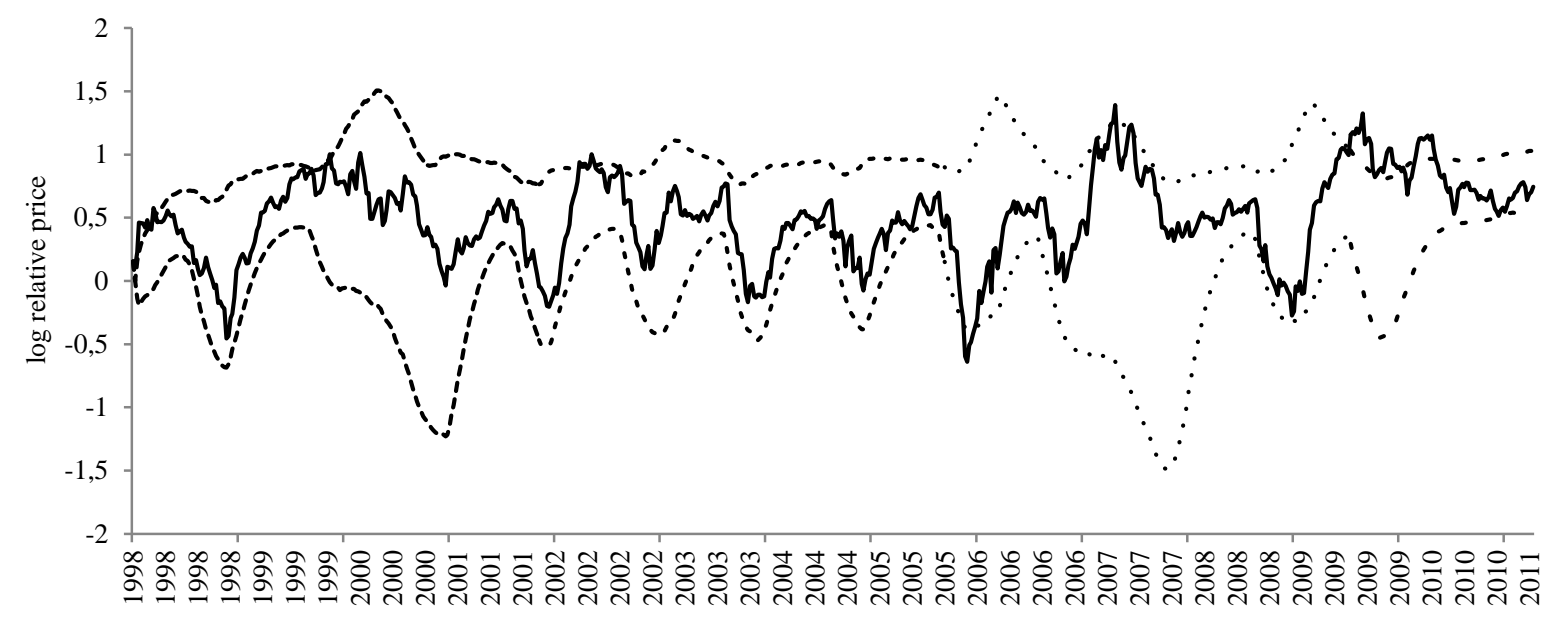

FIGURE 6. 5\% and 95\% confidence intervals of simulated prices along with observed relative prices.

The 5\% and 95\% confidence intervals for the simulated series are shown in figure 6 . We observe that the simulated prices are stable despite one of the regimes (regime 2) having an autoregressive coefficient close to 1 . This is because prices regularly change to a regime (regime 1) with relatively strong mean-reversion. The periods with wider error bands are associated with the decoupled regime (regime 2). We observe how the model can account for peak-load pricing, although the uncertainty of prices in this regime is large. For 2007, for example, relative prices were high in the spring and summer with no peak-load pricing in the winter. There is evidence of decoupling (regime 2 is predicted) although with no apparent peak-load gas pricing effect.

It is also of interest to examine how temperature affects the probability of changing regimes. Looking at smoothed probabilities, prices tend to change from regime 1 to regime 2 in early September, and then change back to regime 1 in February. These periods are associated with the start and end of fall/winter gas pricing. The fact that regime shifts occur throughout our sample suggest that demand is the main driver, and that deregulation has had limited impact. To illustrate how the transition probabilities depend on temperature we plot the likelihood of changing regimes as a function of temperature. This is shown in figure 7. The effect is largest in moving from regime 1 to regime 2 (from integrated to decoupled markets). The probability of a switch increases in temperature. When temperature is high, demand is low, and demand is more likely to switch and start increasing. This is due to the highly cyclical nature of demand for natural gas. This switch is most likely to occur in late summer when mean temperatures eventually starts decreasing. Demand will then start moving outwards on the supply-curve and peak-load pricing might occur. 


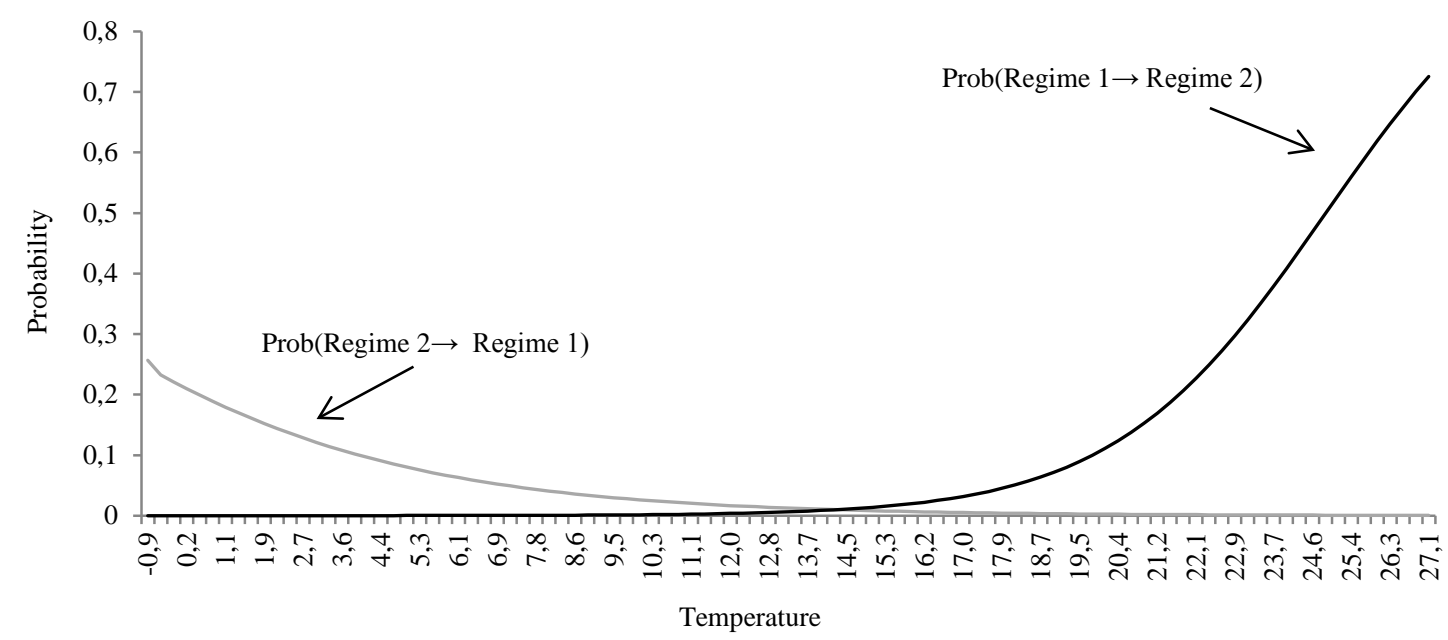

FIGURE 7. The effect of temperature on the probability of changing regimes.

When calculating the historical relative value of oil to natural gas, we should account for the periods where evidence points towards decoupled markets. In these periods gas is priced as a unique commodity in itself. The gas is valued predominantly by its marginal productive value in generating electricity/heating at that specific point in time. If we use the periods where evidence is strongest for an integrated market (regime 1) we find that the mean relative value of oil to natural gas on an equivalent energy basis is 2.33 . Thus mean relative value is higher than the previously assumed rule of thumb of 2.0. This is reasonable if the rule of thumb did not account for peak-load pricing. Our model illustrates that mean reversion in relative prices is dependent on the time of the year. Most of the reversion back to oil occurs in spring and summer when demand for gas to heating and electricity is low and net-availability and transport capacity are high. Using evidence for when markets are decoupled (regime 2) we find that for $49 \%$ of the sample the markets where decoupled.

Our empirical results do not indicate that peak-load pricing has become more prevalent in later years. There is no clear evidence of underinvestment in capacity after deregulation of gas markets in the UK. Considering the general increase in demand for natural-gas, capacity has likely increased as a response to growing demand. This would leave net availability similar across the sample period. Fears of underinvestment in capacity following deregulation seem unfounded. Our results do not contradict previous findings of integrated markets, but rather provide a more detailed picture of the relationship, emphasizing that markets occasionally decouple due to gasspecific pricing, and switches between being decoupled and integrated. 


\section{Concluding Remarks}

The fact that gas demand tends to be seasonal (Asche et al., 2008), together with limited transfer capacity, suggest that peak load pricing is possible. A number of studies (Serletis and Herbert, 1999; Asche et al., 2006; Panagiotidis and Rutledge, 2007) suggest that the relationship between the oil and the gas price is stable over time when using a linear specification. This paper incorporates the non-linear effects of peak-load pricing on the dynamics of relative prices, showing that the UK natural gas marked switches between two states. We do this by applying a regime shifting model where pricing can change between cointegrated and decoupled (peak-load) prices. While electricity markets experience extreme price peaks of short duration, the storing option for natural gas suggests less extreme price variation and a smoother shift between seasonal pricing regimes.

Accounting for peak-load pricing is relevant when evaluating the long-run relative value of oil to natural gas. Our model distinguishes between a mean-reverting/integrated regime and a decoupled pricing regime. The model can account for periods where gas-specific demand determined the value of gas. These will be the traditional peak-load pricing periods. Accounting for these periods we find that relative prices revert to a ratio of approximately 2.3. This means that in periods on cointegration Brent is on average approximately 2.3 times more valuable than natural gas on an energy equivalent basis. This is different from the previously assumed 2.0 rule of thumb, and provides an indication of the bias caused by not accounting for the non-linear dynamics.

Our results show that relative prices tend to revert in the spring/summer when demand for natural gas for heating and electricity generation is lower. The estimated regimes suggest that in periods natural gas in the UK is priced independently of oil. This does not imply that relative prices are not stable in the long-run. As long as natural gas reverts back from peak-load pricing a stable relative price regime is still established. The existence of two pricing regimes suggests that deregulation has partly been able to create a separate price determination process for natural gas. However, as the regime shift occurs on an almost annual basis, temperature conditions seem to be the main driver of the regimes rather than increased competition. 


\section{References}

Ang, A. and G. Bekaert (2002). "Regime Switches in Interest Rates", Journal of Business and Economic Statistics, 2002(20):163-82.

Asche, F., O. Gjølberg and T. Völker (2003). "Price Relationships in the Petroleum Market: An Analysis of Crude Oil and Refined Product Prices”, Energy Economics, 25, 289-301.

Asche, F., P. Osmundsen and R. Tveterås (2002). ”European Market Integration for Gas? Volume Flexibility and Political Risk”, Energy Economics 24: 249-265.

Asche, F., P. Osmundsen and M. Sandsmark (2006). “The UK Market for Natural Gas, Oil and Electricity. Are the prices decoupled?”, The Energy Journal 27: 27-40.

Asche, F., O. B. Nilsen and R. Tveteras (2008). "Natural gas demand in the European household sector”, The Energy Journal 29(3): 27-46.

Bachmeier, L. J. and J. M. Griffin (2006). “Testing for Market Integration: Crude Oil, Coal and Natural Gas” Energy Journal 27(2): 55-72.

Bansal, R., G. Tauchen and H. Zhou (2004). "Regime Shifts, Risk Premiums in the Term Structure, and the Business Cycle”, Journal of Business and Economic Statistics, 22(4):396-409.

Bencivenga, C., G. Sargenti and R. D’Ecclesia (2011). “Integration of energy commodities in Europe and the USA”, Journal of Risk Management in Financial Institutions, 4(3): 301-13.

Brown, S. P. A. and M. K. Yucel (2008). “What Drives Natural Gas Prices?”, Energy Journal, 29(2): 45-60.

Castle, J.L. and Hendry, D.F. (2010). “A low dimensional portmanteau test for non-linearity”, Journal of Econometrics, 158(2):231-45.

De Vany, A. and W. D. Walls (1993). "Pipeline Access and Market Integration in the Natural Gas Industry: Evidence from Cointegration Tests”, The Energy Journal 14: 1-19.

Diebold, F.X., Lee, J.H. and Weinbach, G.D. (1994). "Regime-switching with time-varying transition probabilities”, Federal Reserve Bank of Philadelphia, No. 93-12 in Working Paper.

Deaton, A., and G. Laroque (1996). “Competitive Storage and Commodity Price Dynamics”, The Journal of Political Economy, 104(5): 896-923.

-. (1992). “On the Behaviour of Commodity Prices”, The Review of Economic Studies, 59:1-23.

Doane, M. J. and D. F. Spulber (1994). “Open Access and the Revolution of the U.S. Spot Market for Natural Gas”, Journal of Law and Economics 37(October): 477-517.

Erdös, P. (2012). “Have oil and gas got separated?” Energy Policy, 49: 707-718. 
Geman, H., and A. Roncoroni (2006). “Understanding the Fine Structure of Electricity Prices”, Journal of Business, 79:1225-1262.

Garcia, R. and P. Perron (1996). “An Analysis of the Real Interest Rate Under Regime Shifts”, The Review of Economic and Statistics, 78(1):111-125.

Gray, S. F. (1999). "Modeling the conditional distribution of interest rates as a regime-switching process", Journal of Financial Economics, 42(1):27-62.

Hamilton, J. D. (1989). “A New Approach to the Economic Analysis of Nonstationary Time Series and the Business Cycle”, Econometrica, 57(2):357-384.

Hamilton, J.D. and R. Susmel (1996). “Autoregressive Conditional Heteroskedasticity and Changes in Regime”, Journal of Econometrics, 64:307-333.

Hamilton, J.D. (1994). “Time Series Analysis”, Princton University Press.

Kanamura, T., and Ohasi, K. (2007). “On Transition Probabilities of Regime Switching in Electricity Prices”, Energy Economics, 30:1158-1172.

Lucia, J., Schwartz, E. (2002). “Electricity Prices and power derivatives: evidence from the Nordic power exchange”, Review of Derivatives Research, 5:5-50.

Mount, T.D., Ning, Y., and Xiaobin, C. (2006). "Predicting Price Spikes in Electricity Markets using a Regimeswitching Model with Time Varying Parameters”, Energy Economics 28(1):62-80.

Panagiotidis, T. and E. Rutledge (2007). “Oil and gas markets in the UK: Evidence from a cointegrating approach”, Energy Economics, 29:329-347.

Ramberg, D.J. and J.E. Parsons. (2012). “The Weak Tie Between Natural Gas and Oil Prices”, The Energy Journal, 33(2):13-35.

Pirrong, C. (2012). Commodity Price Dynamics: A Structural Approach. Cambridge University Press.

Silverstov, B., G. L'Hegaret, A. Neumann and C. von Hirschhaussen (2005). “International Market Integration for Natural Gas? A Cointegration Analysis of Prices in Europe, North America and Japan”, Energy Economics 27: 603-615.

Serletis, A. and J. Herbert (1999). “The Message in North American Energy Prices”, Energy Economics, 21(Oct): 471-483.

Wright, B.D. and J.C. Williams. (1991). "Storage and Commodity Markets”, Cambridge University Press, Cambridge. 